\title{
'GIRLS WANNA HAVE FUN'?: EL VERSO SUELTO HUMORÍSTICO DE LA POESÍA DE DOROTHY PARKER EN LOS 'ALEGRES' AÑOS VEINTE
}

\author{
FrANCISCO JOSÉ CORTÉS VIECO \\ Universidad Complutense de Madrid
}

Recibido: 15/09/2014

Aceptado: 24/11/2014

\section{Resumen}

El corpus poético de Dorothy Parker trasciende el retrato de una socialite y de una época mítica: Nueva York durante los «alegres» años veinte. Debajo de ritmos de jazz, diversión nocturna y luces de neón en esta ciudad, residen malestares públicos y privados en la realidad femenina. El humor ingenioso y corrosivo del universo lírico de esta autora estadounidense actúa como una coda subversiva de modernidad hacia la invectiva social y de género, que suaviza o refuerza su trágica autobiografía de desamor y depresión, a la vez que desnuda sus pulsiones creativas, que universalizan, abrazan y rechazan paradigmas contemporáneos de feminidad. Pese a la burla del canon literario que empequeñece su legado, Parker es la última en reír porque su comedia, anfibia entre negra y diáfana, ilustra el ansiado acceso de la mujer a una poesía y un humor propios.

Palabras clave: humor, drama, mujer, hombre, sociedad, diversión, amor, infelicidad.

\begin{abstract}
Dorothy Parker's corpus of poetry transcends the portrait of a socialite and mythic times: New York in the Roaring Twenties. Underneath jazz rhythms, fun nights and the neon lights of this city, public and private female anxieties remain. The witty, but caustic, humor in this American writer's verses plays the role of a subversive, modern coda that criticizes social and gender inequalities. This does not only attenuate or strengthen her tragic biography of unrequited love, but it also universalizes, embraces and detaches its author from models of contemporary femininity. Despite the mockery of the literary canon that minimizes her legacy, Parker laughs last because her
\end{abstract}


comedy, from black to bright, illustrates women's ultimate access to their own poetry and humor.

Keywords: humor, drama, woman, man, society, amusement, love, unhappiness.

Feminismo/s 24, diciembre 2014, pp. 265-287 
«La raza humana solo tiene un arma verdaderamente efectiva, que es la risa»

Mark Twain

\section{Introducción: la mujer y su comicidad}

Es un atavismo artístico que el humor haya sido siempre catalogado como un pasatiempo sin trascendencia, una extravaganza destinada al entretenimiento del lector y denigrada, en ocasiones, por su propio creador o creadora. Con frecuencia, se ha localizado en las antípodas de la literatura «seria»-novela y teatro-, que es aquélla abocada a poder ser coronada con la solemnidad y la inmortalidad del canon literario. Sin embargo, el humor ha sido y es hoy en día un elocuente artefacto estético y/o con fines sociales, que pretende llamar la atención del público con mensajes «serios», camuflados debajo de artificios jocosos o triviales. En consonancia, corrientes historicistas entienden que la tradición de las letras en el ámbito anglonorteamericano desde los siglos XVIII y XIX, con figuras clave como Jonathan Swift, Alexander Pope, William Thackeray, Ambrose Bierce o Mark Twain, ha apelado a la sátira y la ironía como «guerrilla» escrita para combatir, o tan solo debatir, verdades absolutas, dogmas inamovibles e ideologías hegemónicas de cada periodo histórico. Sin ser necesariamente atacadas por estos y otros literatos masculinos, dichas corrientes de pensamiento se sustentan en un entramado patriarcal de desigualdad de género, desde instituciones políticas hasta esferas privadas como la familia. Frente a esta tónica generalizada, una subcultura femenina, embrionaria en la época victoriana con escritoras como Charlotte Brontë, George Eliot, Kate Chopin o Charlotte Perkins Gilman, se ha atrevido a cuestionar, rebelarse o invalidar la falacia de la inferioridad física, psíquica e intelectual de la mujer con respecto al hombre, pero no desde la comicidad subversiva, sino desde la queja, la ira, el drama personal o el activismo feminista.

Barbara Levy sostiene que, tradicionalmente, las mujeres no han podido mostrarse divertidas ni con sentido del humor por culpa de la vinculación de 
su propio ingenio con el hecho de ser «brujas o putas» ${ }^{1}$. Este axioma de la cultura occidental habría conectado su peligrosa inteligencia con su presunto poder para manipular a los hombres o desafiar los roles domésticos impuestos en su contra por voluntad humana y divina. En sintonía con la censura de su voz por parte del Establishment literario, las escritoras se han visto igualmente privadas del uso y disfrute de su agudeza mental y de juegos semánticos, intrincados y sofisticados, que son imprescindibles para crear el humor. De ahí que éstas hayan sufrido un doble hándicap: la inaccesibilidad al mismo y la falta de libertad para inventar una versión propia, alejada de su dócil mímesis de patrones masculinos de este arte «informal» y denostado. Uno de los primeros y más ilustres «versos sueltos» con novedosa autoría de una mujer es la estadounidense Dorothy Parker (1893-1967).

\section{Dorothy Parker o «el verso suelto» de su tiempo}

A continuación, pretendemos explorar las convergencias y las divergencias entre el universo lírico y otro cómico en la obra de esta escritora, o triste «mujer-chiste» de Nueva York en los «alegres» años veinte, su etapa de mayor producción literaria, durante la cual logró ser una celebridad gracias a su estilo propio, verbo fácil y desbordante hilaridad. Marion Maude afirma que tuvo un cariño especial por su padre y que, cuando era pequeña, una manera de complacerle era redactar versos para hacerle reír ${ }^{2}$. En conjunción con la tradición humorística puramente norteamericana desde Mark Twain y el gusto de Parker por el epigrama procedente de fuentes clásicas, esta génesis paterna en su creación «menor» detectaría la influencia masculina que acabamos de mencionar, la cual se canalizó durante su vida adulta a través de su ardiente deseo de satisfacer a su público fiel y sus expectativas, una vez que se consagró como paradigma de la autora cómica en la poderosa nación norteamericana. Polifacética y camaleónica, fue poetisa, narradora de relatos cortos, ensayista, guionista y crítica teatral, que trabajó y publicó en diversas revistas neoyorquinas, como Vogue, Vanity Fair, New Yorker o Lady's Home Journal. De igual manera, frecuentó los círculos literarios y periodísticos más selectos de la urbe y fue miembro de la famosa Tabla Redonda del Hotel Algoquin. Rabiosamente desenfadada y con intensidad autobiográfica, la siguiente estrofa en «Grandfather said it», detecta la problemática social y familiar de la vocación

1. LEVY, Barbara (coord.). Ladies Laughing: Wit as Control in Contemporary American Women Writers. London \& New York, Routledge, 1997, p. 1.

2. MeAdE, Marion. «Introduction». Complete Poems of Dorothy Parker. London, Penguin, 2010, p. xvii. 
artística de la mujer en los inicios del siglo XX. Bajo una cosmética de sarcasmo y burla, el abuelo de la joven prefiere para su nieta cualquier profesión, incluso si ésta es delictiva, denigrante o sin glamour, antes que la deshonra de que sea escritora en un futuro:

'Clean out ferryboats; peddle fish;

Go be chorus men if you wish;

Rob your neighbors' houses in the dark midnight;

But think of your families, and please don't write's.

Contraria al deseo de su familia, u opresora institución patriarcal, Dorothy Parker trabajó y escribió durante su vida, sin depender durante mucho tiempo de la seguridad económica de su primer marido y para compensar la ruina financiera tras una niñez en un entorno acomodado y el fallecimiento de su padre. En «Song of one of the girls», se posiciona incluso como la heredera de una pléyade -desnutrida en número- de mujeres históricas, míticas y literarias con carisma y determinación, como Eva, Dido, Safo, Lady Hamilton o Madame de Staël, que está predestinada a la gloria de la inmortalidad:

I'm one of the glamorous ladies,

At whose beckoning history shook.

But you are a man, and see only my pan,

So I stay at home with a book ${ }^{4}$.

Estas últimas líneas exaltan la profesionalización de su vocación artística y atacan las expectativas domésticas del hombre con respecto a la mujer, a la vez que dibujan una mujer indiferente al afecto, la pasión y las responsabilidades familiares, que prefiere la soledad de la lectura. Pese a ello, un surtido rastro de indicios en el corpus poético de Dorothy Parker delatan su autoengaño: no aspirar a amar y ser amada por un hombre. Proyectando una imagen pública de socialite alocada y divertida, se distrajo, flirteó y disfrutó, como mujer y artista, en un marco espaciotemporal mítico e irrepetible: la burbujeante y convulsa década de los años veinte en los Estados Unidos. Amenizada por el jazz, los clubs nocturnos, las luces de neón, el alcohol y las vanguardias, soplaron en aquellos momentos nuevos vientos de optimismo, cambio, progreso, consumismo y capitalismo; de prosperidad económica y tecnológica con el desarrollo del automóvil, el cine, la moda o las telecomunicaciones,

3. PARKer, Dorothy. Complete Poems. London, Penguin, 2010, p. 309. «Limpia barcos; vende pescado;/ Conviértete en voz del coro si lo deseas;/ Roba en la casa de tus vecinos a medianoche;/ Pero piensa en tu familia, y no escribas» (traducción propia).

4. Ibíd., p. 72. «Soy una de esas damas glamurosas/ Cuyo atractivo cautivó a la historia/ Tú tan solo eres un hombre que ve mi sartén/ Por lo que me quedaré en casa con un libro» (traducción propia). 
así como de auge de ciudades cosmopolitas con Nueva York a la cabeza. En un intento por olvidar el fracaso humano y los horrores de la Primera Guerra Mundial, el humor fue un antídoto o una terapia hacia la recuperación anímica de una sociedad y una literatura aún moribundas tras la sangre derramada. La autora perteneció a una generación «no perdida» de artistas que, frente a la libertad estética que sus errantes coetáneos Gertrude Stein, T.S. Eliot, Henry Miller o Ernest Hemingway sí lograron durante su exilio europeo, decidió permanecer en suelo patrio. James Gaines sostiene que, movidos por la necesidad económica, Parker y otros miembros de la Mesa Redonda del Algonquin entendían que la escritura era un medio más para ganarse la $v_{\text {vida }}{ }^{5}$. Este imperativo monetario, además de las presiones del mercado editorial y periodístico, estrangularían la soberanía estética de la propia escritora. En «Song for the first of the month» demuestra que el dinero no garantiza la felicidad del ser humano: «Money, spite of all its pow'r,/ Cannot purchase ruddy health $»^{6}$. Pese a ello, es honesta y prosaica al admitir, como colofón de su poema, que las constricciones de la vida cotidiana -tales como comprar comida o pagar el alquiler cada mes- impiden el adorno de esta composición con creencias ilusorias y utópicas, poco ancladas a la existencia rutinaria del individuo: «Try to tell the butcher so/ [...] Laugh the landlord off with that! $\gg^{7}$, la cual sería fuertemente hostil y vulgar. En estas últimas estrofas, se sugeriría que el chiste de Parker se asocia, intuitivamente, más a una realidad «fea» que a ideales «hermosos», o a una causalidad y narrativa en verso, en disonancia con la exploración de la belleza o de conceptos abstractos, que ha sido la materia prima par excellence de la lírica desde tiempos inmemoriales. A diferencia de corrientes humorísticas sureñas o de los suburbios acomodados en los Estados Unidos a principios del siglo XX, la comicidad en el arte de Parker es eminentemente urbana y cosmopolita, por lo que no solo rechazará, sino que abofeteará la propensión de la laureada poesía romántica por la naturaleza paisajística y su ósmosis con la psique del artista. En «Song for an April Dusk», la ensoñación y la fantasía que bañan los parajes campestres no invitan al deleite y sí al hastío: «Tell me tales of lilied pool/ Asleep beneath the sun $[\ldots]$ / And, boy, will I be bored! $»^{8}$. Mientras tanto, la estrofa inicial de

5. GAINES, James R. (coord.). Wit's End: Days and Nights of the Algonquin Round Table. New York, Harcourt Brace Jovanovich, 1977, p. 124.

6. PARKER, Dorothy. Op. cit., p. 264. «El dinero, pese a todo su poder, no compra la buena salud» (traducción propia).

7. Ibíd., p. 264-265. «Intenta contárselo al carnicero/ [... ¡ ¡El casero se lo tomará a broma! (traducción propia).

8. Ibíd., p. 344. «Cuéntame relatos de estanques llenos de nenúfares/ Adormecida bajo el sol [...] $]$ Y, chico, ¡¡cómo me aburrirás!» (traducción propia). 
«Song of the Wilderness» refleja su predilección por el asfalto y la cosmética de Nueva York, sin olvidar los cómicos versos sueltos entre corchetes de quien aclara que prefiere quedarse en casa descansando, y no sufrir las alergias $\mathrm{u}$ otras contingencias del medio natural:

We'll go out to the open spaces,

Break the web of the morning mist,

Feel the wind on our upflung faces.

[This, of course, is if you insist.]

We'll go out in the golden season,

Brave-eyed, gaze at the sun o'verhead.

[Can't you listen, my love, to reason?

Don't you know that my nose gets red?]

Where the water falls, always louder,

Deep we'll dive, in the chuckling foam.

['ll go big without rouge and powder!

Why on earth don't you leave me home? $]^{9}$

Desde el éxito de su primer volumen de poesía Enough Rope (1926), Dorothy Parker se vio obligada a no divorciarse jamás de la comedia. Este género literario simultáneamente actuaría como freno a su creatividad artística y como su única «pareja fiel», a la cual su público la casó sin su tácito consentimiento: si no estaba alegre o feliz en su interior, al menos debía fingir divertirse en su vida y poder divertir con su obra de cara a su exigente y entregada audiencia. Kevin Fitzpatrick relata anécdotas sobre cómo los neoyorquinos, que eran los principales admiradores de su verso mordaz, perseguían a Dorothy por la calle o en veladas sociales para que dijera algo gracioso; e incluso, se reían a carcajadas, sin sentido, antes de que ella pudiera articular palabra alguna ${ }^{10}$. Pese a ello, la autora ejerció su derecho a proyectar la sátira social en su corpus lírico, lanzar dardos (in)ofensivos contra hombres y mujeres, o exhibir malestares internos, dolor y traumas en su jardín secreto en verso, pero siempre con remates de humor que atenúan la beligerancia de su querella. Poemas como «Fulfilment» revelan que el glamour y la opulencia de la feria de vanidades neoyorquina no garantiza su dicha: «A life of limousined and jeweled ease/

9. Ibíd., p. 325. «Iremos al campo,/ Romperemos la tela de araña de la niebla matutina,/ Sentiremos el viento sobre nuestras caras./ [Esto haremos, por supuesto, si insistes.]/ Saldremos durante la estación dorada,/ Con ojos valientes, miraremos de cara al sol./ [Amor mío, ¿no puedes ser razonable?/ ¿No sabes que mi nariz enrojece?]/ Allí donde cae el agua, con más ruido,/ Bucearemos en sus profundidades, bajo una espuma risueña./ [¡A lo grande, sin colorete y lápiz de labios!/ ¿Por qué cielos no me dejas sola en casa?] (traducción propia).

10. FitzPATRICK, Kevin C. (coord.). A Journey into Dorothy Parker's New York. Berkeley, Roaring Forties Press, 2013, p. 9. 
Is but a round of fathomless ennui ${ }^{11}$. En contraposición, la voz de «Rhyme of an Involuntary Violet» sugiere la ausencia de sus sentimientos amorosos hacia el hombre, su carácter frívolo y práctico como mujer, o el imperativo de la seguridad económica, ya que su autofinanciación parece ser inviable:

Does my smile across a table

Win a cloak of Russian sable?

Baby, no. I'd have to kill a

Man to get a near-chinchilla ${ }^{12}$.

Estas mareas líricas a contracorriente detectarían una de las constantes del arte de Parker: la ambivalencia entre las estrecheces de una vida de bohemia y la holgura del bienestar económico junto a un caballero acaudalado. Asimismo, Rhonda Pettit enfatiza que la moda, la ropa y las joyas metaforizan su interés por posar como modelo, cambiar de identidad, adoptar personalidades ficticias o enmascarar otras muchas con su obra ${ }^{13}$.

\section{Humor y coda tragicómica: cuatro armas de mujer}

Nancy Walker ha identificado cuáles son los tres rasgos esenciales de la literatura humorística de las mujeres estadounidenses: que ésta es menos agresiva y hostil que aquella creada por el hombre, que escriben sobre lo que mejor conocen, y en torno a la incongruencia entre promesa y realidad, ya que su enfoque refleja la desigualdad de género padecida por ellas ${ }^{14}$. La poesía de Dorothy Parker no solo recoge fielmente estas características estéticas, sino que también diagnostica la polaridad entre el legendario «sueño americano», practicable únicamente en versión masculina. Asimismo, detecta la precaria coyuntura femenina, pese a los hitos sociopolíticos alcanzados por la mujer del momento gracias al esfuerzo del feminismo de inicios del siglo XX: su paulatino acceso a la educación universitaria, el mundo laboral y el derecho al

11. PARKER, Dorothy. Op. cit., p. 266. «Una vida agradable con limusinas y joyas/ No es más que un aburrimiento insondable» (traducción propia).

12. Ibíd., p. 358. «¿Puede mi sonrisa al otro lado de la mesa/ Ganarse un abrigo de piel de marta cibelina rusa?/ No, cariño. Tendría que matar a un/ Hombre para conseguir uno que pareciera de chinchilla» (traducción propia).

13. Pettit, Rhonda S. (coord.). A Gendered Collision: Sentimentality and Modernism in Dorothy Parker's Poetry and Fiction. Cranbury, Farleigh Dickinson University Press, 2000, p. 26.

14. WALKER, Nancy A. (coord.). What's so funny? Humor in American Culture. Wilmington, Scholarly Resources Inc., 1988, p. 32. 
voto $^{15}$. Sin embargo, su persistente sujeción económica y psíquica en las relaciones de pareja, no la búsqueda de su independencia profesional y emocional del hombre, es el núcleo narrativo de muchos de los poemas de Parker, en los cuales emplea dos pares de estrategias líricas de corte femenino, o corrientes antagónicas para confesar la omnipresencia del amor y el desamor en sus versos. Por un lado, la generalización de sus vivencias personales y la introspección psicológica hacia sí misma. Y por otro, su identificación con otras mujeres y su desvinculación de éstas mismas. Perteneciente a la primera categoría, «General Review of the Sex Situation» detecta cómo vierte la frustración y la amargura procedente de la experiencia propia hacia la universalización de la situación afectiva de todo el colectivo femenino, sin demarcaciones espaciotemporales, y sí producto tanto de la sabiduría popular como de su propio talento para la ácida observación sociológica:
Woman wants monogamy;
Man delights in novelty.
Love is woman's moon and sun;
Man has other forms of fun.
Woman lives but in her lord;
Count to ten, and man is bored.
With this the gist and sum of it,
What earthly good can come of it? ${ }^{16}$.

Parker sostendría que la mujer resulta ser la perdedora en la llamada «lucha entre sexos», por culpa de su inferioridad de condiciones que está provocada por estructuras sociales, y no por rasgos inherentes a su sexo ${ }^{17}$. No obstante, mostrarse crítica con su coyuntura familiar y sociopolítica no es suficiente para etiquetar a esta autora como feminista porque no proclamó cambios en las relaciones hombre-mujer, ni modeló su propia vida como ejemplo a imitar por sus conciudadanas ${ }^{18}$. Todo lo contrario, ya que, en otras composiciones, reflejaría la vulnerabilidad de quien se siente víctima indefensa, y no una

15. El Fithteenth Amendment, que fue ratificado por el Congreso de los Estados Unidos en 1919, concedía el derecho al sufragio a cualquier ciudadano norteamericano sin distinción de sexo.

16. PARKER, Dorothy. Op. cit., p. 82. «La mujer quiere monogamia;/ Al hombre le encanta la novedad./ El amor es la luna y el sol de la mujer;/ El hombre se divierte de otras maneras./ La mujer tan solo vive para su señor;/ Cuenta hasta diez, y el hombre ya se aburrió./ Este es el quid de la cuestión y se resume en,/ ¿Qué puede haber de bueno en esta situación?» (traducción propia).

17. WALKeR, Nancy A. Op. cit., p. 31.

18. Mitchell, Rebecca. «Dorothy Parker and Ambrose Bierce: A Sardonic Tradition». The ABP Journal 2, 1 (2006), <http://www.ambrosebierce.org/journal2mitchell.html>, consultado el 23-05-2014. 
empoderizada activista que reclama la emancipación de género. «Symptom recital», al igual que muchos otros versos, se adscribiría a la segunda estrategia estética en torno al amor en su corpus lírico: la introspección en su propio soma y psique. Los desórdenes nerviosos y cambios anímicos de una voz en primera persona: «I am not sick, I am not well./ My quondam dreams are shot to hell» ${ }^{19}, \mathrm{o}$ «My soul is crushed, my spirit sore;/ I do not like me any more» ${ }^{20}$, somatizarían un estado emocional deteriorado, que anuncia una conclusión ambivalente. Por un lado, su estado físico de rechazo del sentimiento amoroso al ser este pernicioso. Pero, por otro, su imperiosa ansia de enamorarse de un hombre de nuevo, lo cual diagnosticaría la naturaleza adictiva de las relaciones de pareja: «I shudder at the thought of men.../I'm due to fall in love again $»^{21}$. Este ejemplo pone de manifiesto el gusto estético de la escritora por giros lingüísticos e inversiones argumentales en sus versos, con intensidad sardónica y efectos caricaturescos, que depuró en una sofisticada ars poetica, acuñada por ella misma y que podemos denominar como drama con coda humorística. De hecho, Emily Toth defiende que la peculiar combinación entre lo cómico y lo trágico en Parker es una invención suya ${ }^{22}$. «Idyl» y «The Little Old Lady in Lavender Silk» son dos ilustraciones de una vida plagada de adversidad y desdicha durante el romance y la vida en común entre hombre y mujer, que son rematadas con ironía o humor de forma inesperada, ágil y espontánea. En la primera, sueños de calma, armonía y felicidad que podían haber colmado la vida de la pareja y evitado sufrir los pesares del mundo, son parodiados al final porque son absurdos e impracticables: «Now that you've thought of it seriously -/ Isn't it great that it never can be? $»^{23}$. En la segunda, se imagina a sí misma como una anciana, con un amplio historial de fortuna y desgracias amorosas, que lanza una mirada retrospectiva positiva a su pasado para concluir que el hombre, aquél que le causó tanto placer y ruina, es lo mejor que le pudo haber ocurrido: «Regret is not part of my plan,/ I think (if my memory's

19. PARKER, Dorothy. Op. cit., p. 77. «No estoy enferma, no estoy bien./ Mis sueños de antaño fueron destruidos por completo» (traducción propia).

20. Ibidem. «Mi alma está machacada, mi espíritu dolorido;/ Ya no me gusto más a mí misma» (traducción propia).

21. Ibidem. «Tiemblo tan solo al pensar en los hombres.../ Me toca de nuevo enamorarme» (traducción propia).

22. Тотн, Emily. «Dorothy Parker, Erica Jong, and New Feminist Humor», en Rhonda Pettit (dir.): The Critical Walz: Essays on the Work of Dorothy Parker, Cranbury, Rosemont Publishing, 2005, p. 149.

23. PARKER, Dorothy. Op. cit., p. 256. «Ahora que has pensado en ello seriamente-/ ¿No es estupendo que nunca podrá llegar a ser?» (traducción propia). 
faithful)/ There is nothing more fun than a man! $»^{24}$. Como mujer maltratada psicológicamente por hombres egoístas, el humor en su poesía supondría una terapia vomipurgante hacia la recuperación sentimental, no hacia la venganza retributiva contra sus tiranos, ni el cisma irreconciliable entre los dos sexos. Todo lo contrario. En «The New Love», su cura es la llegada de una nueva ilusión: «At my door's another lad;/ Here's his flower in my hair $»^{25}$, aunque desvele la inseguridad respecto a su físico: «If he see me pale and sad,/ Will he see me fair? $»^{26}$. Rozando la temeridad emocional, su voz en «Folk song» no solo exhibe, festiva y jovial, su modus vivendi que encadena unos amantes con otros, sino que demuestra, impasible, no aprender de sus errores pese a identificarlos con lucidez:

Robin, he is strong and sure,

Gallant, wise, and gay.

Gavin's heart is calm and pure

As the new-born day.

Steady shine young Alan's eyes,

Deep with honesty.

Jack, he tells me naught but lies, -

He's the lad for me [...]

Jack, he's wondrously untrue, -

He's my own dear love.

Casper's hair is golden brown;

Hal is straight and slim.

Martin's richest in the town -

Who'd say 'no' to him?

Rafe's a fine young gentleman;

Tom's with virtue blest.

Jack, he broke my heart and ran, -

I love him the best ${ }^{27}$.

24. Ibíd., p. 165. «Arrepentirme no es parte de mi plan,/ Opino (si mi memoria no me falla)/ Que ¡no hay nada más divertido que un hombre! (traducción propia).

25. Ibíd., p. 25. «En mi puerta, hay otro chico;/ Aquí está su flor sobre mi pelo» (traducción propia).

26. Ibidem. «Si él me viera triste y pálida,/ ¿Me verá guapa? (traducción propia).

27. Ibíd., p. 349. «Robin, es fuerte y seguro,/ Galante, sabio, y alegre./ El corazón de Gavin es tranquilo y puro/ Como un nuevo día./ Inmutables brillan los ojos del joven Alan,/ Profundos, con honestidad./ Jack, no me cuenta más que mentiras, -/ Es el chico para mí [...]/ Jack, es asombrosamente insincero, -/ Es mi querido amado./ El cabello de Casper es castaño dorado;/ Hal es serio y delgado./ Martin es el más rico de la ciudad -/ ¿Quién le diría que 'no'?/ Rafe es un caballero joven y apuesto;/ Tom está bendecido de virtudes./ Jack, me rompió el corazón y huyó, -/ Es el chico que yo más quiero» (traducción propia). 
Con cinismo y descaro, la protagonista de estos versos declara lo que parece ser irremediable en su código genético: preferir a Jack, un embaucador que le hizo sufrir y a quien ama más que a cualquier otro pretendiente sincero y galante que haya conocido. Su frivolidad y este magnetismo innato del «malo» se neutralizan en otros poemas en los que el hombre, o dicho de otro modo, el epicentro de su vida como artista y mujer, se transfigura en la diana de su resentimiento y desprecio. En ellos, se desvanece el humor inofensivo y surge otro más visceral que delata la ambivalencia casi patógena de sus emociones hacia sus parejas. En «To my dog», el perro constituye la metáfora del amado fiel, pero en lugar de reflejar las virtudes características de los canes, tales como honestidad, generosidad y empatía, se sugiere su condición de animal -poco inteligente y humano-, que hace gala de un instinto depredador e irresistible para las «hembras» de la «manada»: "You're frankly, too informal./ And mentally, I sometimes fear,/ You're slightly under normal $»^{28}$. En estos y otros poemas de amor y desamor con germen confesional se evidencia la aguda tensión psíquica y artística de la escritora. Dorothy Parker se debatiría entre la tradición de sus deseos femeninos con alta carga romántica y afectiva -noviazgo, enlace nupcial o, al menos, un compromiso emocional pleno con su «príncipe azul»-, y la modernidad de una sexualidad sin ataduras, que su entorno masculino exigiría a una mujer de su categoría. Si la llamada New Woman ${ }^{29}$ causaba ansiedad y temor en la sociedad patriarcal desde tiempos finiseculares, la flapper $^{30}$, que era su tentáculo durante los años veinte y el «traje a la medida» de Dorothy Parker, se vinculaba, con intensidad misógina, a un modus vivendi femenino caracterizado por la frivolidad, el hedonismo, la irreflexión y la disponibilidad al sexo. La biografía de la poetisa neoyorquina como celebrity y, por lo tanto, ampliamente conocida por el público estadounidense, refuerza su afiliación (in)voluntaria a la diversión, el humor y la trivialidad de este paradigma humano y estético de mujer. De hecho, la prensa rosa de su tiempo también se hizo eco de la cascada de sus amores tormentosos, fracasos matrimoniales, abortos, alcoholismo e intentos de suicidio. Nina Miller argumenta que el vanguardismo en la obra de la

28. Ibíd., p. 260. «Eres francamente demasiado informal./Y mentalmente, a veces me temo,/ Que estás ligeramente por debajo de una inteligencia normal» (traducción propia).

29. Con clara influencia de escritores del momento, este modelo femenino abogaba por un ideario feminista a favor de los derechos sociopolíticos de la mujer, y su emancipación sexual y profesional.

30. Mujeres jóvenes, rebeldes y «alegres» de los años veinte en Estados Unidos con apariencia física, vestimenta y conducta poco convencionales para los estándares de la época: pelo corto, faldas cortas, fumar, beber alcohol, bailar al ritmo del jazz, promiscuidad, o divertirse durante toda la noche. 
autora reside en el tono sofisticado de su malévola feminidad, que atacaba a otras mujeres contemporáneas, y en su osado liberalismo sexual, pese al alto precio que tuvo que pagar: que los hombres le rompieran el corazón demasiado a menudo ${ }^{31}$. En relación con este último aspecto, hemos evocado que su corpus lírico desnuda el lado oscuro del empoderamiento de la flapper: el «animal herido» muestra, al final sin humor, su miedo al cruel rechazo masculino, el duelo por el amor perdido y las secuelas del traumático abandono. En consonancia, algunos poemas, como «Triolets», desvelan un sustrato de vulnerabilidad femenina a través de la sintomática metáfora de la fragilidad de su corazón: «I send you my heart/ Marking it 'Fragile - don't break it'» ${ }^{32}$; y en su resolución, carecen del idiosincrásico verso suelto cómico: «Now you have gone and got married!/ Sweet, I have waited too long;/ Heedless and wanton, I've tarried $»^{33}$. En otros, como «Chant for dark hours», la voz poética de la creadora dramatiza constantes narrativas femeninas: la mujer que aguarda durante largas horas el regreso de su amante a sus brazos, el cual sería un hombre que seduce, pero que nunca cumple sus promesas. Incluso, clama al cielo que su futura pareja no sea otro Romeo inconstante, antes de concluir que la espera es siempre inevitable: «All your life you wait around for some damn man! $»^{34}$. La ausencia de dosis final de comicidad en ambas composiciones aproximaría a Parker más bien a las convenciones literarias en torno al drama del desamor, en manos tanto de hombres como de mujeres desde la antigüedad, por lo que el humor se manifestaría, en otros poemas, como signo inequívoco de modernidad e irreverencia con respecto a la tradición artística. La fijación autodestructiva, también en una vertiente introspectiva aunque sin especificar etiología amorosa, inunda el corpus lírico de una escritora que no sería tan feliz y que no se divertiría tanto a lo largo de los alegres años veinte como sus devotos lectores creían ciegamente. Prosaica y con vocación empírica, sintetizará en su antológico «Résumé»el porfolio de los métodos disponibles, aunque no infalibles, para suicidarse. Insinuará que todos ellos son dolorosos o antiestéticos, antes de sentenciar que la vida también es una

31. Miller, Nina. «Making Love Modern: Dorothy Parker and Her Public», en Rhonda S. Pettit (dir.): The Critical Waltz: Essays on the Work of Dorothy Parker, Cranbury, Rosemont Publishing, 2005, p. 45.

32. PARKER, Dorothy. Op. cit., p. 186. «Te envío mi corazón/ Y lo marco con la mención 'Frágil - no lo rompas'» (traducción propia).

33. Ibidem. "¡Ahora te has largado y te has casado!/ Cariño, esperé demasiado tiempo;/ Con descuido y sin sentido, me he retrasado» (traducción propia).

34. Ibíd., p. 41. «¡Toda tu vidas aguardas que llegue algún maldito hombre!» (traducción propia). 
opción plausible, lo cual equivaldría a su característica coda de imprevisibilidad, pero esta vez poco chistosa y sí muy irónica:

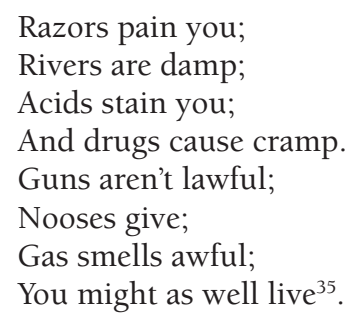

Este poema ilustraría la incursión de Dorothy Parker en la comedia negra, en la cual abordará abiertamente un tabú atemporal, como es la muerte voluntaria, aunque con el maquillaje estético de no desvelar las causas de la ideación suicida y el tono humorístico sombrío de quien, finalmente, no aboga por autodestruirse. Pero tampoco glorificaría la vida y sí somatizaría su desgana o desidia con respecto a ambas alternativas: sobrevivir o desaparecer. La ambigüedad y la mundanidad de esta estrofa, típicas de este género artístico, no es más que la «guinda» que corona un prolijo corpus lírico que no insinúa, sino que exhibe, con frontalidad expositiva y amargura, este mismo drama humano. En «Cherry white», la incongruencia es extrema al confesar, con jocosidad, lo bonito que sería ahorcarse de un cerezo en flor: «How gay 'twould be/ To hang me from a flowering tree' ${ }^{36}$, ya que convergerían en unas mismas líneas el nacimiento primaveral y la desaparición invernal. Mientras tanto, en «Epitaph» enumera cuántas veces intentó quitarse la vida: «The first time I died $[\ldots] /$ The next time I died...» $»^{37}$, con intensidad orgánica y desolación emocional, aunque sin ningún atisbo de regocijo o coda burlesca. Emplee o no el humor la «divertida» Parker para rememorar el horror o la liberación de la muerte voluntaria en sus versos, su obra supone una revolucionaria democratización de la poesía, iniciada por autores decimonónicos como Walt Whitman. Esta efeméride artística, en manos ahora de una mujer neoyorquina, se manifestaría en su extenso uso de coloquialismos y de un lenguaje vernáculo Made in USA, o en su accesibilidad para el gran público más allá de la imperante estética elitista del Modernismo angloamericano, disponible solo para una clientela selecta. Pero sobre todo, este aperturismo

35. Ibíd., p. 51. «Las cuchillas te hacen daño;/ Los ríos están húmedos;/ Los ácidos te manchan;/ Y las drogas dan calambres./ Las pistolas no son legales;/ Los nudos de la horca ceden;/ Los gases huelen fatal;/ También podrías decidir vivir» (traducción propia).

36. Ibíd., p. 158. «Qué bonito sería/ Colgarme de un árbol en flor» (traducción propia).

37. Ibíd., p. 14. «La primera vez que me morí [...]/ La siguiente vez que me morí...» (traducción propia). 
lírico se refleja en sus temáticas con cáliz femenino o infractor en torno al amor y la muerte, que verbalizan o cantan, con énfasis narrativo y confesional, experiencias prohibidas o tragicomedias difícilmente narrables por su falta de decoro.

Con independencia de esta «sobredosis» autobiográfica en su corpus lírico, la escritora neoyorquina cultivó otras dos estrategias poéticas en la aproximación a su vida y a la de sus conciudadanas: la identificación con ellas y la desvinculación de ellas. En ocasiones, su voz subjetiva e introspectiva hacia la autoconfesión se diluye. En sus reflexiones sobre las técnicas literarias de las memorias de escritoras norteamericanas, como los múltiples puntos de vista o las historias colectivas, Isabel Durán localiza su propensión a la hora de otorgar el protagonismo a las «Otras», en calidad de pilar fundacional para definir su propio «Yo» ${ }^{38}$. En sintonía, Parker no hablaría siempre en primera persona, sino que a veces, como en «Biographies», recurre a una polifonía lírica con fines caricaturescos o, tal vez, moralizantes, pero siempre buscando un alter ego divertido, que alimente su propia efigie pública de alegre flapper. En estos versos, la táctica estética de su identificación con otras mujeres surge al comparar dos chicas de familias acomodadas: Marigold Jones y Lucy Brown. La autora describe a ésta última como su antítesis, o la joven virtuosa y obediente que se comporta con decoro y respeta sus roles de hija y hermana: «She $[\ldots]$ would never play with the little boys» ${ }^{39}$. Cuando crece, previsiblemente llegará a ser la esposa perfecta conforme a las inviolables expectativas de la sociedad patriarcal: dócil, elegante e hipócritamente amantísima de su marido millonario. En contraposición, su oscura doppelgänger, Marigold, es una niña traviesa y un tomboy desde pequeña: «She [...] cut off her sister's abundant curls;/ And never would play with the little girls» ${ }^{40}$ que, en cambio, se gana la simpatía y la empatía de la autora y el lector. En edad adulta, también previsiblemente, la narrativa lírica de Parker delata su predilección por el coqueteo y el escándalo público al preferir divertirse con hombres comprometidos, antes que reproducir convencionalismos y etiquetas sociales:

38. DURÁN GIMÉNEZ-RICO, Isabel. «La Estrategia del 'Otro' en la Autobiografía Femenina Americana del Siglo XX». Revista Española de Estudios Norteamericanos 14, 5 (1992), p. 36.

39. PARKER, Dorothy. Op. cit., p. 85. «Ella [...] nunca jugaría con los muchachitos» (traducción propia).

40. Ibíd., p. 86. «Ella [...] cortó los abundantes rizos de su hermana;/Y nunca jugaría con otras muchachitas» (traducción propia). 
And once there was talk of a married man!

She sauntered in public in draperies

Affording no secrecy to her knees;

She constantly uttered what was not true;

She flirted and petted [...]

And people remarked, in sepulchral tones.

'You'll see what becomes of Marigold Jones'41.

A diferencia de la herencia victoriana aún reinante en la moralidad imperante de las primeras décadas del siglo XX, el «buen» comportamiento no se recompensaría en el universo moderno de Parker, mucho más realista que las reminiscencias decimonónicas. En esta misma línea, a la díscola Marigold, al final del poema, no le espera la desgracia, sino el mismo destino de domesticidad y respetabilidad que a Lucy, el cual no sería necesariamente afortunado, y sí estaría determinado por su estatus social privilegiado. Si bien esta coda humorística detecta la obligatoriedad de la falsedad y la duplicidad en la vida pública y privada de la mujer contemporánea, también sería el espejo de la filosofía y la biografía de la propia escritora, que recomendaría a sus conciudadanas divertirse mientras que son solteras y libres, al igual que practican sus futuros maridos sin estigmatización social. A primera vista, en «Moral Tales for the Young [I]», Dorothy Parker se identificaría con otra joven coetánea, ficticia o no, que es osada, inteligente y manipuladora, en una jungla urbana regida por el dinero y la usura sin mesura ${ }^{42}$.

Maude, the brightest of the sex,

Forged her daddy's name to checks,

Took them to the local banks,

Cashed them, with a smile of thanks.

All the money came in handy -

Maudie was so fond of candy!

Weight she gained in way affrighting,

So she's given up her writing.

Save the money, when you forge;

Little ladies do not gorge ${ }^{43}$.

41. Ibidem. «¡Una vez hubo una conversación sobre un hombre casado!/ Ella caminaba en público en paños menores/ Sin dejar lugar al secreto;/ Constantemente decía lo que no era verdad;/ Flirteaba y acariciaba [...]/ Y la gente opinaba, en tono sepulcral./ 'Ya verás qué será de Marigold Jones'» (traducción propia).

42. Este poema podría evidenciar la devoción de Dorothy Parker por su maestro, el victoriano William M. Thackeray y su famosa novela Vanity Fair (1848), con su arribista y astuta heroína Becky Sharp.

43. Ibíd., p. 278. «Maude, la más inteligente entre las chicas,/ Falsificaba la firma de su padre en los cheques, / Los llevaba a los bancos del lugar,/Los cobraba, con una sonrisa de agradecimiento./ Todo el dinero era útil -/ ¡A Maudie le encantaban las golosinas!/ 
Pese a la indeseable secuela del sobrepeso que fortalece la hilaridad del poema, la codicia de Maude simbolizaría la exaltación de su ingenio. La joven contaría con la complicidad de la autora a la hora de celebrar la habilidad femenina para gestionar su vida, pero resultaría ambiguo afirmar que el fin justifica sus medios egoístas. Asimismo, Parker recurriría a la estrategia estética de la desvinculación para distanciarse de su heroína y acusarla de materialista ante su lector masculino. Este juego de ambivalencia textual ilustraría la definición de parodia, que es un recurso humorístico clásico cultivado por la autora neoyorquina. Para Linda Hutcheon, es una noción de síntesis que incorpora un texto marco a la narración para captar una diferencia y crear, de este modo, efectos cómicos y serios, unos burlescos que vierten críticas, mientras que otros delatan confabulación ${ }^{44}$. Los quebrantamientos generados por este concepto serían, paradójicamente, autorizados por las normas oficiales que pretenden ser subvertidas para garantizar así su continuidad ${ }^{45}$. En consonancia, la autora apoyaría subrepticiamente la malicia de Maude, pero atacaría su rapacidad públicamente, en connivencia con normas sociales e intereses masculinos. Aunque la subcultura literaria femenina desde el siglo XIX se cimentaba en la solidaridad y la sororidad entre mujeres, todas bajo el mismo yugo patriarcal, el humor de Parker halla en ellas su víctima ideal. El miedo de su compatriota, actriz y colega Anita Loos a su brillante mente y afiliada pluma es una clara evidencia ${ }^{46}$. Al igual que se esmeró por agradar a su padre de niña, Dorothy ridiculizó en sus versos a otras mujeres con fines paródicos y de desafección por el género femenino en su conjunto. Su papel de distante y despiadada observadora, pretendería compensar la sobreexposición mediática de su propia vida en su obra lírica. En «On Being a Woman», ofrece argumentos misóginos que, presuntamente, apoyan aquellos clichés masculinos que, de forma ancestral, insisten en la inconsistencia e inconstancia en los sentimientos y afectos de la mujer, que sería "genéticamente» inestable y caprichosa:

Why is it, when I am in Rome

I'd give an eye to be at home,

But when on native earth I be,

My soul is sick for Italy?

And why with you, my love, my lord,

Engordó de forma pasmosa,/ Por lo que dejó de escribir./ Ahorra tu dinero, cuando falsificas;/ Las jovencitas no se atiborran» (traducción propia).

44. HutcheOn, Linda (coord.). A Theory of Parody. London, Methuen, 1985, p. 54-55.

45. Ibíd, p. 75.

46. Hammil, Faye (coord.). Women, Celebrity, and Literary Culture between the Wars. Austin, The University of Texas Press, 2007, p. 28. 
Am I spectacularly bored,

Yet do you up and leave me - then

I scream to have you back again ${ }^{47}$.

En obediencia con la tradición artística masculina, la voz de «Pagean» celebra el esplendor de la naturaleza y una felicidad, que su soma y su psique rezuman, antes de confesar en su verso suelto la banal causa de su alegría: «For I have lost a pound!» ${ }^{48}$. Pero este desprecio de Parker hacia la mujer no siempre es mundano y trivial al detectar su volubilidad y su culto al cuerpo, sino que su feroz ataque irá in crescendo en otras composiciones. En «Women: A Hate Song», la autora brinda caricaturas grotescas e hieráticas, exageradas o calcadas, de solteras y casadas sin personalidad propia. Éstas no son el reflejo de lo que ellas son en realidad como seres humanos, sino de lo que deben fingir ser o la imagen de artificio que deben proyectar, según los hegemónicos cánones estéticos e ideológicos de los «alegres» años veinte en los Estados Unidos, fuertemente arraigados al capitalismo y al consumismo. La discordia y disociación de Parker con estos modelos femeninos es evidente desde los primeros versos: «I hate Women./ They get on my Nerves» ${ }^{49}$, que podrían articular una diatriba propia, en primera persona; o ser ella misma tan solo la ventrílocua de voces masculinas a las que apoyaría: «They are pests./ They know everything on earth/ And will tell you about it gladly ${ }^{50}$. Por culpa del conflicto que crean entre iconografía e identidad femenina, Angela Weaver sostiene que la autora odió la representación genérica de las mujeres en la cultura periodística de la publicidad y las revistas de moda de aquel entonces, porque éstas dibujaban una falsa felicidad en sus rostros ${ }^{51}$. Ella misma trabajó en algunas de estas publicaciones, con el deber tácito de reverenciar los ideales domésticos de dicha conyugal y abnegación femenina, a pesar de su deseo de pisotear al déspota -el hombre- y a la víctima -su aliada, la esposa sumisa-. No obstante, sí logró materializar esta última pulsión estética en poemas cómicos, aunque cargados de violencia feminicida y caracterizados

47. PARKer, Dorothy. Op. cit., p. 124. «¿Por qué cuando estoy en Roma/ Daría lo que fuera por estar en casa,/ Pero cuando me encuentro en mi tierra,/ Mi alma añora Italia?/ $\mathrm{Y}$, ¿̇por qué contigo, mi amor, mi señor,/ Me aburro soberanamente,/ Pero entonces cuando tú te marchas-/ Grito para que regreses a mí de nuevo?» (traducción propia).

48. Ibíd., p. 333. «¡Porque he perdido una libra de peso! (traducción propia).

49. Ibíd., p. 207. «Odio a las mujeres. Me atacan los nervios» (traducción propia).

50. Ibíd., p. 208. «Ellas son una pesadas./ Saben todo de este mundo/ Y te lo dirán con gusto» (traducción propia).

51. WeAVER, Angela. «'Such a Congenial Little Circle': Dorothy Parker and the Early-Twentieth-Century Magazine Market». WSQ: Women's Studies Quarterly 38, 3 \& 4 (2010), pp. 33-34, p. 35. 
por su deliberado distanciamiento de paradigmas de género, sin importarle en apariencia la perpetuación de patrones misóginos de sometimiento de la mujer. En «Rosemary», la diana de su burla serían las técnicas de cortejo masculino y su lenguaje amoroso. La autora se travestiría en hombre para satirizar las expectativas románticas de la poesía y de la amada con la glorificación de su belleza, que solo sería un artificio con palabras huecas y embusteras:

I wear your fragant memory, like a spray of mignonette,

As I tread the winding ribbon of the years.

How clear the radiant image of your stands before me yet

In the thousand little mirrors of my tears.

And ah, my dearest love, when I forget the way to dream

I'll forget your silent nearness in the dark,

Where languorous lilies floated on a quiet woodland stream

Or were you the one I'd meet in Central Park ?52. $^{2}$.

Sin embargo, no será hasta el clímax humorístico del final cuando el lector perciba que estos versos no simbolizan una oda al amor, con imágenes sensoriales, ensoñación y profusión floral a la antigua usanza, sino que verbalizan la charlatanería sarcástica y alambicada de quien se ríe del sujeto, el objeto y el producto poético: «Your name is ever written on the pages of my heart, -l And, by the way, my dear, what was your name? $\aleph^{53}$. La parodia residiría en la convivencia en el mismo texto de la crítica velada a la seducción del hombre con fines sexuales y la ridiculización de la mujer, con el deseo de la autora de obtener la complicidad de una audiencia masculina. Pero esta ilustración de cómo el amante no se interesa por quien es o cómo se llama la amada no es más que el avant-gôut del feroz insulto y la humillación a la destinataria de los versos en «Sonnet [1]», donde Parker vuelve a demostrar la importancia del peso corporal para el público femenino:

As roses' passionate hearts, your mouth is red;

Like lilies in the wind, your long white hands.

Brighter the glance of you than summer star;

But, lady fair, how awful thick you are! $!^{54}$.

52. PARKER, Dorothy. Op. cit., p. 345. «Llevo impregnada tu memoria embriagadora, como un espray de reseda,/ Mientras piso el ondulado lazo de los años./ ¡Qué clara se posa tu radiante imagen delante de mis ojos!/ En los miles de espejitos de mis lágrimas./Y, ¡ah!, mi amor, cuando olvide cómo soñar/ Olvidaré tu silente proximidad en la oscuridad,/ Allí donde lánguidos nenúfares flotaban en un tranquilo arroyo del bosque / O ¿eres tú con quien me toparía en Central Park?» (traducción propia).

53. Ibidem. «Tu nombre está escrito en las páginas de mi corazón,-/Y, a propósito, encanto, ¿cuál era tu nombre?» (traducción propia).

54. Ibíd., p. 316. «Como los apasionados corazones de las rosas, tu boca es encarnada; Como los lirios al viento, tus largas manos son blancas./ Más brillante es una mirada 
Regina Barreca afirma que la escritora utiliza el humor para reclamar algún tipo de control y poder sobre su propia vida ${ }^{55}$. Enemistad, celos o venganza, estos versos que exaltan la lozanía del objeto poético para finalizar con una coda cómica mediante la cual se mofa de su gordura, podrían no ser ataques contra genéricos modelos femeninos promovidos en las revistas de moda, sino contra personas de carne y hueso, e identificables al pertenecer al círculo social de la autora. Más flagrante sería el humor cáustico que Dorothy Parker exhibe en «To Myrtilla, on Easter Day», donde describe la exposición pública de una grácil y perfecta dama de la alta sociedad antes de concluir «I hope she breaks her neck! » ${ }^{56}$. De igual manera, el epílogo de «To a Lady» detecta sus ansias de ver sufrir, o incluso perecer, a otra mujer porque es enemiga o antagónica: «Not a man you meet that doesn't fall for you;/ Lady, pretty lady, how I hope you choke! $\aleph^{57}$. En estas dos composiciones, se revelaría que la voz poética podría ser la de la propia escritora o, al menos, una genuinamente femenina que no experimentaría las permutaciones de género masculino observadas en otras, como «Rosemary»o «Sonnet [1]». El germen de su táctica literaria de desvinculación podría ser la rivalidad o la envidia hacia otras mujeres dibujadas en sus versos. Éstas, quizás, serían más bellas y modélicas que ella, pero siempre resultarían ser las ganadoras, porque sí se convertirían en las amadas a largo plazo o las esposas de los hombres que rompen el corazón de la graciosa -pero derrotada- Dorothy, la desprecian y, al final, la abandonan por otra. Cerrando el círculo narrativo de su poesía y bajo tupidas capas de comicidad, esta estrofa de «Frustration» vuelve a reflejar su ira y sus instintos homicidas con intensidad autobiográfica:

If I had a shiny gun

I could have a world of fun

Speeding bullets through the brains

Of the folk who give me pains ${ }^{58}$.

Mientras que el espejo del rencor en su arte es la confesión, aderezada de humor o no, en su vida real es, en cambio, el daño hacia sí misma -un largo

tuya que una estrella estival;/ Pero, bella dama, iqué terriblemente gorda estás!» (traducción propia).

55. BARRECA, Regina (coord.). Untamed and Unabashed: Essays on Women and Humor in British Literature. Detroit, Wayne State University Press, 1994, p. 12.

56. PARKER, Dorothy. Op. cit., p. 292. «iEspero que se rompa el cuello!» (traducción propia).

57. Ibíd., p. 317. «No hay ningún hombre que conozcas que no caiga rendido a tus pies;/ Dama, bella dama, ¡espero que te caigas de bruces!» (traducción propia).

58. Ibíd., p. 132. «Si tuviera una pistola brillante/ Tendría un mundo lleno de diversión/ Las balas atravesarían los sesos/ De la gente que me hace daño» (traducción propia). 
calvario del alcohol y raptos suicidas-, no el ajuste de cuentas contra la o el causante de tanto daño psíquico.

\section{Conclusión: quien ríe la última..., ríe mejor}

Dorothy Parker personifica el drama del artista que se dedica a entretener y hacer reír al público, siendo su profesión el garante de su mueca sardónica en el texto, pero no de que realmente se divierta en su vida y con su obra. El humor es el elixir de sus epigramas y codas, pero igualmente un arma de doble filo. Por un lado, es un ilimitado recurso que avala la modernidad de su corpus lírico, porque su verso suelto cómico actúa como una reflexión perspicaz, afilada y crítica, con mensajes francos que esclarecen la ambigua argumentación narrativa de sus tristes estrofas. Pero por otro, es limitador al teñir a sus poemas de tintes autobiográficos, ya que estos se transforman en números circenses, o vodevil melodramático de desamor, angustia y deseos de muerte emulando a su propia experiencia personal. La autora tuvo que pagar un alto precio por ser una chica «alegre» con escándalos sentimentales plasmados en los tabloides y que ansiaba «divertirse» con el uso del «informal» verso cómico, porque el Establishment académico de su época la condenó al estatus de figura menor de las letras estadounidenses, asociada solo a su aura de starlette sofisticada y frívola del panorama mediático de Nueva York en los míticos años veinte, no a sus méritos literarios. Sin embargo, su talento reside, primero, en su vanguardismo solvente al despreciar o parodiar antiquísimos convencionalismos estéticos del amor romántico, el silencio de la mujer, su victimismo y seriedad sin derecho a la carcajada. Y segundo, se sostiene en la atemporalidad y pluralidad interpretativa de sus poemas, regados por el equívoco de sus estrategias líricas. Principalmente, destacan dos de las cuales han sido identificadas y exploradas a lo largo de este artículo. Por un lado, el alejamiento emocional en el retrato de paradigmas femeninos -reales, abstractos o fabricados por una manufactura patriarcal-, porque los aborrece. Y por otro, la profunda introspección psicológica, ya que sus composiciones dramatizan los vaivenes de su propia vida, rebosante de luces y sombras: entre la desdicha y las ganas de amar y ser amada, distraer y distraerse.

El poder de las poetisas-humoristas es que son ellas las que «siempre ríen las últimas $»^{59}$. Tras su larga espera, así como la de sus antecesoras -tanto conocidas como olvidadas-, Dorothy Parker sí rió en vida al acceder a un humor propio, que igualmente (des)cubre injusticias de género y dramas

59. Darlington, Tenaya. «Funny Grrls: Humor and Contemporary Women Poets». Humor 22, 3 (2009), p. 340. 
sentimentales. Y, a pesar de las trabas del Establishment patriarcal y la tradición estética de la obligatoria ausencia de «gracia» en la literatura femenina, la autora ríe todavía hoy en día, porque ha conseguido arañar la inmortalidad artística, asociada a unas coordenadas espaciotemporales concretas: Nueva York durante los años veinte. Como muestra de su triunfo en «Inventory», que podría ser su propio epitafio, la mujer moderna abandona, por fin, su (in) deseado pedestal de objeto del poema -ideal, musa y modelo- para llegar a ser sujeto soberano del mismo, que vence a los traumas, los enemigos y a las malas experiencias del pasado, gracias a su sabiduría, ingenio hilarante y a una sana frivolidad femenina:

Four be the things I am wiser to know:

Idleness, sorrow, a friend, and a foe.

Four be the things I'd been better without:

Love, curiosity, freckles, and doubt.

Three be the things I shall never attain:

Envy, content, and sufficient champagne.

Three be the things I shall have till I die:

Laughter and hope and a sock in the eye ${ }^{60}$.

La mirada retrospectiva de Dorothy Parker en estos últimos versos resume, a modo de epílogo, el leitmotiv de su experiencia tragicómica, con autoridad legítima para su reconversión literaria en autobiografía y observación sociológica de género en su país y su tiempo: la prevalencia de la diversión espumosa en su propia vida, y el poder de autoconocimiento, superación y creatividad que emana de la risa y la burla, incluso hacia sí misma y sus miserias, sin caer en el desaliento, la inactividad o el hastío.

\section{Referencias bibliográficas}

BARRECA, Regina (coord.). Untamed and Unabashed: Essays on Women and Humor in British Literature. Detroit, Wayne State University Press, 1994.

DARLINGTON, Tenaya. «Funny Grrls: Humor and Contemporary Women Poets». Humor 22, 3 (2009), pp. 329-340.

DURÁN GIMÉNEZ-RICO, Isabel. «La Estrategia del 'Otro' en la Autobiografía Femenina Americana del Siglo XX». Revista Española de Estudios Norteamericanos 14, 5 (1992), pp. 36-47.

60. PARKER, Dorothy. Op. cit., p. 44. "Que sean cuatro las cosas que deba saber para ser más sabia:/ Vaguería, pena, un amigo y un enemigo./ Que sean cuatro las cosas que prefiera no tener:/ Amor, curiosidad, pecas y dudas./ Que sean tres las cosas que nunca obtenga:/ Envidia, conformidad y suficiente champán./ Que sean tres las cosas que posea hasta la muerte:/ Risa, esperanza y un golpe en el ojo» (traducción propia). 
GAINES, James R. (coord.). Wit's End: Days and Nights of the Algonquin Round Table. New York, Harcourt Brace Jovanovich, 1977.

HammiL, Faye (coord.). Women, Celebrity, and Literary Culture between the Wars. Austin, The University of Texas Press, 2007.

HutCheOn, Linda (coord.). A Theory of Parody. London, Methuen, 1985.

LEVY, Barbara (coord.). Ladies Laughing: Wit as Control in Contemporary American Women Writers. London \& New York, Routledge, 1997.

MeAdE, Marion. «Introduction». Complete Poems of Dorothy Parker. London, Penguin, 2010.

Miller, Nina. «Making Love Modern: Dorothy Parker and Her Public», en Rhonda S. Pettit (dir.): The Critical Waltz: Essays on the Work of Dorothy Parker, Cranbury, Rosemont Publishing, 2005, p. 44-61.

MitCHELl, Rebecca. «Dorothy Parker and Ambrose Bierce: A Sardonic Tradition». The ABP Journal 2, 1 (2006), <http://www.ambrosebierce.org/journal2mitchell. html>, consultado el 23-05-2014.

PARKer, Dorothy. Complete Poems. London, Penguin, 2010.

PETTIT, Rhonda S. (coord.). A Gendered Collision: Sentimentality and Modernism in Dorothy Parker's Poetry and Fiction. Cranbury, Farleigh Dickinson University Press, 2000.

Tотн, Emily. «Dorothy Parker, Erica Jong, and New Feminist Humor», en Rhonda Pettit (dir.): The Critical Walz: Essays on the Work of Dorothy Parker, Cranbury, Rosemont Publishing, 2005, pp. 137-151.

WALKer, Nancy A. (coord.). What's so funny? Humor in American Culture. Wilmington, Scholarly Resources Inc., 1988.

Weaver, Angela. "Such a Congenial Little Circle': Dorothy Parker and the Early-Twentieth-Century Magazine Market». WSQ: Women's Studies Quarterly 38, $3 \& 4$ (2010), pp. 25-41. 